\title{
Kansas Leadership Studies Summit: Cultivating Collaborative Capacity for the Common Good
}

\author{
Kerry L. Priest \\ Kansas State University \\ Brandon W. Kliewer \\ Kansas State University \\ Clinton M. Stephens \\ Emporia State University
}

\begin{abstract}
Bringing together leadership educators from 11 programs in Kansas, the Leadership Studies Summit fostered new initiatives and strengthened collegial networks. The summit responded to local and national expressed needs for intensive dialogue focusing on collaboration and capacity building among leadership educators for advancing the common good. This application brief will share the format and outcomes of this dialogue, including recommendations for future multi-institutional collaborations.
\end{abstract}

\section{Introduction}

It has been widely expressed that more and better leadership is needed at all levels of society; indeed, this call has served as a catalyst for building the leadership capacity of young adults through our colleges and universities (e.g., Zimmerman-Oster \& Burkhardt, 2000). Higher education institutions have both contributed to the development of students' leadership capacity and continuously expanded the access to education - with public institutions in the United States have been on the forefront of these efforts. In contemporary times, our state has taken on the mantle of leadership education more directly.

Kansas is home to 11 academic programs at colleges and universities, the highest concentration of curricular programs in any state (National Clearinghouse for Leadership Programs, 2016), as well as the Kansas Leadership Center, a non-profit organization committed to fostering leadership for stronger, healthier, and more prosperous communities, plus the United State Army's Command and General Staff College at Fort Leavenworth. In 2016 an author, Stephens, conducted a learning tour of leadership programs. Through informal interviews and a systematic analysis of program documents (Kliewer \& Stephens, 2017), two themes were clear: (1) a common focus on change guided by civic values, and (2) an interest for increased collaboration and communication with leadership educators across the state. The call for collaboration across programs also reinforces national trends. Recently, the InterAssociation Leadership Education Collaborative (2016) put forth a critical priorities report based on the assumption that while leadership education provides a platform for addressing critical challenges facing local and global communities: 
Considerable work is necessary to address the gap between our aspirations for a better society and evidence of real and lasting change ... leadership education organizations and associations can and should bridge this gap and increase boundary-spanning efforts to advance leadership education and development for the next generation. (ILEC, 2016, p. 2).

The ILEC priorities document also identifies three critical focus areas for action: (1) building inclusive learning communities, (2) expanding evidence-based practice through assessment and evaluation, and (3) enhancing our community of practice through professional development and resources (2016). We believe Kansas leadership educators are poised to make progress, not only in advancing the teaching and learning of leadership, but also in facilitating social change and community development - both of which are priorities articulated within the National Leadership Education Research Agenda (Andenoro et al., 2013).

This application brief highlights the intentional design of a summit convened in May 2017 for faculty and staff affiliated with Kansas Leadership Studies Programs. The purpose of the summit was to advance the common good through collaboration and build capacity among leadership educators across programs in Kansas. We will situate our work in a broader framework of capacity building for community and social change. Additionally, we will describe the intentional design of the summit, as well as initial outcomes and potential impact. Our reflection and recommendations may serve to guide leadership educators in other geographic regions to also initiate cross-campus collaborations.

\section{Review of Related Scholarship}

Leadership for What? "Leadership for what?" is an essential organizing question for leadership practitioners, educators, and students. Assuming that leadership is socially constructed and values-based (Dugan, 2017) means that the implicit and explicit beliefs, principles, and values shaping our programs have direct implications for pedagogy and leadership practice. The theoretical and conceptual framework for this project is informed by laying a leadership lens over humanity's call for change (e.g., United Nations' Sustainable Development Goals, Declaration of Human Rights, Earth Charter and others), pointing towards values and practices of socially responsible leadership.

Socially responsible leadership can be conceptualized through the Social Change Model (SCM) of Leadership Development (Higher Education Research Institute, 1996), which Owen (2012) found the most prevalent framework used by leadership studies programs. The SCM assumes that "change... is the ultimate goal of the creative process of leadership - to make a better world and a better society for self and others" (p. 21). Grace suggests that in order to effectively engage the world's greatest challenges in more sustainable, caring, and just ways, leaders must embrace a common good worldview: moving from only concern for self and one's group towards a conscious concern for the good of all (2011). Chrislip and O'Malley's call for civic leadership echoes "an expanding circle of concern...feeling and taking a broader sense of responsibility for civic concerns that recognizes our individual complicity in these problems, and thus our responsibility for helping make progress on them" (2013, p. 159). 
The implication for leadership educators, then, is to embrace the responsibility of helping people not only learn about leadership, but also engage in the activity of leadership - through and with the classes, programs, institutions, and communities of which they are a part - toward a common good.

Exercising Leadership. With this framing in mind, we consider, then what kind of leadership practices are required to create the conditions for people to accept responsibility to make progress towards change? We draw from practices of adaptive leadership (Heifetz, Grashow, \& Linsky, 2009) and strategic social change leadership (Dugan, 2017; Ospina et al., 2012). Adaptive leadership assumes that complex challenges require more than technical solutions generated by experts, but rather a commitment to learning, renegotiating power and authority, involving multiple voices and perspectives, and taking on an experimental mindset to progress (Heifetz et al., 2009). O’Malley and Cebula (2015) merge a common good mindset with the practices of adaptive work, offering a framework for diagnosing and making progress on tough challenges facing our organizations and communities. They suggest one of the hardest parts of exercising leadership is working across factions, or various stakeholder groups, to understand values, loyalties, and losses to leverage strengths and connections. Dugan (2017) proposes that applying a critical sense-making lens to adaptive leadership practice creates further possibilities for adaptive work to be a collaborative, co-constructed learning process.

Strategic social change leadership (Ospina et al., 2012 as cited in Dugan, 2017) is motivated by recognition of the realities of systemic inequality and visions of human well-being and justice. Long-term change to structures, policies, and thinking require leadership activities (e.g., organizing, advocacy, community building, and service provision) facilitated through leadership practices of reframing discourse, bridging differences, and unleashing human energies (2017). When deployed at across levels of capacity (individual, organizational, and interorganizational), the "practices are the sources from which leadership emerges" (2017, p. 302). This gives new dimension to leadership for the common good, as the leadership practices themselves co-construct new understandings of leadership required to enact social change.

Leadership educators who seek to develop the capacity for social change in studentsand enact social change through leadership learning - are well served to employ pedagogies of practice (Ganz \& Lin, 2012) that create the conditions for engaging in adaptive practices for strategic social change.

Deliberative Dialogue as Leadership Practice. Ganz (2011) suggests that leadership on behalf of social change requires telling a public story: "a story of self, a story of us, and a story of now" that communicates our deeply held values and invites others to join us in making progress on an urgent challenge (p. 282). Kliewer and Priest (2016) adapted this public narrative framework into a multi-stage community storytelling approach for deliberative dialogue that creates the conditions for collaborative civic leadership activity.

Deliberative civic engagement is a civic leadership activity that convenes people for constructive, informed dialogue around important public issues (Nabatchi, 2012). Spaces of deliberative civic engagement operate within what Drath (2001) frames as a relational dialogue principle of leadership meaning-making. Grounded in this perspective, Ospina and Schall 
articulate how leadership resides in the social system, with conditions of uncertainty and complexity (2001). Leadership is practiced "when people with different worldviews use dialogue and collaborative learning to create spaces where common purpose can be achieved while diversity of perspectives is preserved and valued" (Ospina \& Schall, 2001, p. 14).

The purpose of the Leadership Studies Summit was to advance the common good through collaboration and build capacity among leadership educators across programs in Kansas. A convening of leadership educators using a deliberative civic engagement approach aligns theory and form. Our learning was an act of leadership - by creating space for deliberation and intentional co-production of meaning we embodied the very philosophies and practices of leadership we sought to develop.

\section{Description of the Practice}

The one-day summit was held on May 17, 2017 at the Emporia State University campus. The 34 participants in the summit represented faculty members, staff, and partners from 11 of 13 total programs, including public and private universities, community college, a command and General staff college associated with the U. S. Military, and non-profit organizations. A general overview of the schedule is included in the table below.

Table 1. Overview of Leadership Summit Schedule

\section{$\underline{\text { Time }} \underline{\text { Activity }}$}

8:00 a.m. Registration and breakfast refreshments

8:30 a.m. Welcome and orientation

8:45 a.m. Story of Self - Poster introductions and connections

10:00 a.m. Break

10:15 a.m. Story of Us - Open space focusing, self-organizing into small groups, and initial discussions

11:45 a.m. Lunch Break - Self-organizing lunch groups

1:15 p.m. Continued small group work time focused on powerful propositions, summarizing, and potential actions

2:30 p.m. Story of Now - Whole group sharing and meaning making, considering "What's next?"

3:30 p.m. Individual reflection on learning, personal application, and next steps

3:45 p.m. Public commitments

4:00 p.m. Conclude 
Next, we describe in more detail the design of our deliberation, including the activities and prompts utilized to facilitate various stages of the process.

Story of Self. The summit began with an introductory session, emphasizing participants' "story of self," or personal call to leadership (Ganz, 2011). Around the walls of the large meeting room were blank sheets of poster paper, one for each participant. Participants were invited to write their name, institution, and three points responding to the prompt: "What brought you here today, what do you want to learn, and/or what interests do you want to share with this group." Then, participants moved around the room in a "gallery style" to review others' posters, and respond by writing comments, questions, or connections. Upon completion, participants returned to their own poster and reviewed the comments. Finally, each participant made a verbal introduction to the group, sharing one aspect they found interesting from this exercise or what was written on their poster by others.

Story of Us. Guided by the idea of a "story of us," we sought to develop shared values that shaped our collective identity and purpose (Ganz, 2011). We utilized a modified "open space" approach - an intentional process of connecting, inviting ideas, focusing ideas, and selforganizing that allowed individuals to move freely to whatever work group they felt they could best contribute and or learn (Herman, n.d.). First, the group identified themes generated by the stories. The initial themes identified (assessment and evaluation; coaching; global/international education; lifespan learning; networking and leadership educator development; and women and leadership) served as focus areas for morning work sessions, with the goal of discussion and dialogue to further diagnose the challenges related to the topic and how we might collectively make progress. Each group captured their action (discussion) on separate Google Doc linked to a master online folder. The first round of discussion was guided by the following prompts:

- What work is already being done around this topic/area?

- Why is this a priority for you personally? For your institution? For our state? For the field of leadership studies/leadership education as a whole?

- What are the gaps, urgent needs, or critical questions related to this area?

- What knowledge, skills, and perspectives are necessary for leadership educators to enact this work?

- What are some key resources that exist?

- What resources are needed to support learning in this area?

- Who are other stakeholders or partners in this work and how do we engage/mobilize them? (e.g., community partners, organizations, other departments)

- How does this priority connect leadership education practices (teaching and learning with our students/communities) to broader outcomes of change at individual, group, or society levels?

- What are some ideas for collaborative action in this area?

The lunch break provided an additional opportunity for community building. Participants self-selected into groups which dispersed among four local restaurants. The optional prompts for lunch conversation were designed to allow for storytelling about self, programs, and communities: 
- How did you become a leadership educator?

- What is the purpose/mission of your leadership studies program?

- What are some innovative ways you are making progress on that purpose? What are some challenges you face?

- How do you see yourself as a leader in your institution and/or community?

- What is the most pressing need/issue facing your community? And, what is your program doing to make progress on that need?

After lunch we returned to work sessions. Through the open-space approach, participants narrowed down the work to four primary areas: coaching, global and international education, women and leadership, and networking/leadership educator development. The next round of discussion was guided by an explicit goal of creating a synthesis of our work in the form of powerful propositions and action steps about the future of Kansas leadership education. The work time was guided by the prompts, (a) "What if?", b)"Then ...", and (c)“How?" "What if?" surfaced our vision of change in our students and state-a preferred future or the change we hope for. "Then" represented the outcome we expected to see from that change. And finally, "how" led us to strategies and actions necessary to make progress on that vision.

Story of Now. Identifying shared challenges of our community, as well as the choices we must make and the outcomes we aspire make up our "stories of now" (Ganz, 2011). The final session of the day invited groups to report back their propositions to the larger group. We then invited the whole group into a conversation about reactions to the ideas and insights shared, as well to answer the question, "Where do we go from here?" in the pursuit of action items. Finally, participants were invited to reflect and write their "next stories" (Kliewer \& Priest, 2016), or personal commitments for next steps, on their original poster. We concluded with a time for public commitments, in which individuals verbalized their next stories to the whole group. Some examples included commitments to collaborate on curriculum, to influence our state legislature, and to host a future Summit. These action steps and additional outcomes will be discussed further in the next section.

\section{Discussion of Outcomes}

We collected and analyzed data from the event (Google Docs and other written notes). Additionally, we administered a post-session evaluation to gain feedback on participants' perceptions of the experience, significant learning, and action steps. An initial review of evaluation data suggested that all respondents ( $n=26$ out of 34 participants) agreed or strongly agreed that they made or strengthened professional relationships at the Summit.

Significant Learning. A cornerstone of our conceptual framework is that to exercise leadership requires learning (Heifetz, et al., 2009; O’Malley \& Cebula, 2015). Participants responses to the question "Describe your most significant learning or experience at the Summit" could be organized around three categories. First, participants valued learning about other programs in Kansas, including various approaches to leadership education and multiple areas of focus. Second, forming connections by getting to know other leadership educators in the state fostered a spirit of collaboration and sense of energy possibility for the future. And third, it was a valuable time of idea generation. Participants noted that they enjoyed the process, or ways in 
which we interacted at the event (e.g. introductions and discussions), and also learned more about the various topical areas of focus (e.g., women and leadership; global education; and coaching).

Working Group Summaries. The open space work time surfaced what was urgent and important to participants in the moment, with an eye on the future. Through storytelling and dialogue, we engaged in the leadership practice of what Ospina et al. (2012) call "reframing discourse" (p. 272). The outcome was not a comprehensive plan, but rather, a starting point for diagnosing challenges and priorities, plus imagining strategies for advancing a more just and equitable future.

Leadership coaching. The leadership coaching working group had interest in two main areas: (1) demonstrating a link of leadership coaching with learning, development, and positive community impact; and (2) exploring forms of learning and development required to support leadership coaching readiness for individuals. Advancing these objectives could lead to greater understanding of how leadership coaching, as a learning and development practice, increases the capacity of systems to exercise leadership for change. In the context of higher education, leadership coaching was seen as an intervention that has the potential to improve retention, persistence, and degree completion. In community and community-engaged scholarship contexts, leadership coaching was seen as a practice that has the potential to advance change efforts and deepen the types of learning required to make systems or adaptive change. While there are many resources available for leadership coaches, there seems to be fewer resources available on what it takes for an individual to make the most of leadership coaching experiences. Powerful propositions from the leadership coaching working group pointed towards the integration of coaching for first semester students in leadership studies programs, the development of a network of leadership coaches, and increased exploration of coaching readiness.

Global and international education. The working group identified various types of global and international education offered across the state - ranging from a large international program; sending graduate and undergraduate students on global experiences and international service teams; and hosting institutes/programs in our own state for international leaders. Critical areas of consideration included: (1) How to acknowledge and account for cultural differences around leadership and citizenship, (2) The need for comparative leadership studies that can provide access to leadership work happening in different cultures and contexts, and (3) Making sense of global leadership within a business context/translating into civic contexts. A primary focus of collaboration was generated around the question: "How do we help prepare our Kansas students to live in a different place or work with different people (across citizenship status, geographical location, national origin, ethnicity, religion, race, class, gender, ability, nuerodiversity, etc.)?" Participants identified an opportunity to create an "anthology" or collection of leadership stories that share inclusive practices of global and international leadership without our own state. 
Women and leadership. A focus of this conversation was on identifying the challenging realities for women and girls in educational spaces, workplaces, and communities. While it is known that the diversity women bring to teams and organizations increases collaboration, teamwork, and development-dominant approaches and perspectives of leadership continue to reinforce stereotypically male styles. Navigating those stereotypes can be culturally and socially risky, requiring heightened attention to systems, identity, relationships, and power dynamics that may be invisible to men. Preparing all students to engage in more inclusive ways requires us to create constructive spaces to have conversations around our own hidden biases. We must bring "unusual voices" (the people whose voices and faces have been overlooked in the dominant leadership discourse), not only to the table (O'Malley \& Cebula, 2015), but to the center of our leadership work (see also Guthrie, Jones, \& Osteen, 2016; Tillapaugh \& Haber-Curran, 2017). Educators can play a role in critically examining the intersectionality of systems (capitalism and consumerism) and social identities (race, class, and gender) in perpetuating not only leadership stereotypes but oppressive practices. What if we teach leadership in a way that is uncoupled from gender? Then we are creating the conditions for more diverse leadership activity that increases people's capacity to see themselves as agents of change.

Leadership educators and programs. This working group was the broadest in focus with discussion ranging from program practices to developmental considerations in our work to educator qualifications and credentialing. In many ways connecting to ILEC's (2016) critical priorities, there is a desire to develop collaborative opportunities for educators across our organizations, increasing our capacity to create and share best practices. At the same time, there is a need to develop our identities as leadership educators in order to better understand backgrounds and experiences that contribute to effective leadership education. If we as educators see ourselves as facilitators of change in multiple systems, then we must develop the capacity (knowledge, skills, and motivations) not only in our students but in ourselves. We value the associations and organizations within our field and recognize that we can also influence and shape these groups. Becoming more purposeful and organized to advance transdisciplinary perspectives allows us to shape and be shaped by the communities in which we reside. If we could get more comfortable with the political nature of our work, then we can move past the labels to see the variances within our many stakeholders. To be effective as change agents, we must be intentional about the recruitment and development of leadership educators to increase diverse representation that is more reflective of society at large.

Identified Action Steps. Several participants identified action steps at the individual level relating to the application of learning to their own classrooms. Others described the Summit as a valuable professional development experience, and expressed a desire to stay connected with the group. However, most named action steps that represented collaborative, cross-institutional work, around four primary themes: (1) continuing the event/collaboration, (2) scholarship (research, assessment and writing activity), (3) connecting programs, and (4) collaborative course and program development. 
Program Follow Up Committee. The participant evaluation included an invitation to join a working committee to follow up on the ideas discussed at the event, as well as ideas surfaced in the evaluation. A Facebook group was created (Kansas Leadership Educators Network). We anticipate the coordinating team to initiate quarterly check-ins (via conference call or video conference) to invite participants to provide updates on their initiatives and encourage collaborative coaching and support.

\section{Reflection of the Practitioners}

The gap between leadership education programs' espoused values of social change and lack of documented sustainable impact surfaces a systemic, adaptive challenge in our field. To make progress requires us - leadership educators - to exercise leadership. This project sought to model inclusive, inter-group collaborative practices necessary to advance leadership education in our state and across the field. Our approach was informed theoretically and conceptually by contemporary perspectives that emphasize leadership for the common good. Drawing from leadership practices that support the activity of social change, this event highlighted the potential leadership studies programs in Kansas can have to be change agents within and across communities.

Ospina and Foldy (2016) suggest that "leadership does not reside exclusively in the leader, but is also a property of the collective (group, organization, social system)" (p. 1). While we the authors were conveners of the Leadership Studies Summit, the "leadership" is evidenced by the work of the collective. The Summit was a starting point for the development a "community of practice" (Wenger, 1998), in this case a network of peers who provide support, guidance, and collaboration to others in the field. Seemiller and Priest $(2015,2017)$ emphasize the importance of a community of practice for leadership educator professional identity development that help people learn what to do, how to be, and what it means to be a leadership educator. A more formalized community of practice may also ensure the sustainability and growth of Kansas leadership education, not only reproducing what currently exists, but pushing the boundaries towards something new, and negotiating the multiple personal, professional, and civic communities that overlap and inform our work.

\section{Recommendations}

Attention to Relationships. The importance of building relationships is welldocumented in leadership and organizing literature (e.g., relational models, organizing models). Ospina et al. (2012) identify community building, "developing social capital and collective efficacy to act on behalf of a group with a common identity," as a core leadership activity in pursuit of social change (p. 276). Before the Summit was ever conceived or convened, there had already been extensive one-to-one, formal and informal relationships established between leadership educators in the state. Thus, the Summit did not create a system or network of leadership education professionals; rather, the event made operations within and across the system visible, and created opportunities to talk with others about the systems of leadership education and development in Kansas in very intentional, strategic, and productive ways. It is important for our community to maintain relationships through communication and engagement - both in person and online. For those who are looking to establish a Summit in their own state 
or region, attention must be given to relationship building early in the process.

Attention to Language and Identities. The Leadership Studies Summit focused on convening individuals holding leadership educator roles; however we anticipate future initiatives to include staff, students, and community that have some role in increasing the capacity of leadership in others. It seems important to continue to reflect on the intentional ways we define "leadership education", as our understanding of where, how, and when leadership education and development takes place can both expand or limit access to participation For example, individuals and organizations who are committed to increasing the leadership capacities of others were not present at the Leadership Summit because they do not regularly take on a leadership educator identity. These individuals and organizations might not use the language of leadership or operate in a formal educational setting, but are committed increasing the agency, capacities, and skills in others. Future summits will consider how to extend invitations to participate in ways that include individuals and organizations that do not directly see themselves as leadership educators.

Attention to Design. Others that are interested in convening similar summits should spend time intentionally constructing participatory methods that engage the participants. The efforts required to support effective collaboration across institutions need to be connected to shared values and processes of change. In order to cultivate the necessary commitments and dispositions, participants need to be given space to ensure that the substance of the discussion and format in the meeting in consistent with the theoretical underpinning of the social construction framework described in the literature review. A close attention on the relationship between theory and practice ensures that the convening is consistent with form and content.

Attention to Future Research. The work of leadership for social change calls for community-engaged, critical, and participatory inquiry methods (Priest \& Kliewer, 2017). We invite leadership educators to think of themselves not only as teachers, but as scholarpractitioners who can co-create and respond to important questions about the efficacy of our programs and their impact on individuals and communities. 


\section{References}

Andenoro, A. C., Allen, S. J., Haber Curran, P., Jenkins, D. M., Sowcik, M., Dugan, J. P., \& Osteen, L. (2013). National leadership education research agenda 2013 - 2018: Providing strategic direction for the field of leadership education. Retrieved from Association of Leadership Educators website: http://leadershipeducators.org/ResearchAgenda

Chrislip, D. D., \& O'Malley, E. (2013). For the common good: Redefining civic leadership. Wichita, KS: Kansas Leadership Center Press.

Drath, W. (2001). The deep blue sea: Rethinking the source of leadership. San Francisco: JosseyBass.

Dugan, J. P. (2017). Leadership theory: Cultivating critical perspectives. San Francisco: JosseyBass.

Ganz, M. (2011). Public narrative, collective action, and power. In S. Odugbemi \& T. Lee (Eds.), Accountability through public opinion: From inertia to public action (pp. 273-289). Washington, DC: The World Bank.

Ganz, M., \& Lin, E. S. (2012). Learning to lead: A pedagogy of practice. In S. Snook, N. Nohria, \& R. Khurana (Eds.), The Handbook for teaching leadership: Knowing, doing, and being (pp. 353-366). Thousand Oaks, CA: Sage.

Grace, B. (2011). Sharing the rock: Shaping our future through leadership for the common good. Bellevue, WA: Common Good Works.

Guthrie, K. L., Bertrand Jones, T., \& Osteen, L. (Eds.). (2016). New Directions for Student Leadership: No. 152. Developing culturally relevant leadership learning. San Francisco, CA. Jossey-Bass.

Heifetz, R. A., Grashow, A., \& Linsky, M. (2009). The practice of adaptive leadership: Tools and tactics for changing your organization and world. Boston, MA: Harvard Business Press.

Higher Education Research Institute. (1996). A social change model of leadership development (Version III). Los Angeles, CA: University of California Higher Education Research Institute.

Herman, M. (n. d.) Working in open space: A guided tour. Retrieved from http://openspaceworld.org/wp2/explore/guided-tour/

Inter-Association Leadership Education Collaborative. (2016). Collaborative priorities and critical considerations for the field of leadership education. Retrieved from the National Clearinghouse of Leadership Programs: https://nclp.umd.edu 
Kliewer, B. W., \& Priest, K. L. (2016). Creating the conditions for political engagement: A narrative approach for community-engaged scholarship and civic leadership development. In K. M. Soria \& T. D. Mitchell (Eds.), Civic engagement and community service at research universities: Engaging undergraduates for social justice, social change and responsible citizenship (pp. 47-62). London: Palgrave Macmillan UK.

Kliewer, B. W. \& Stephens, C. M. (2017). Understanding Leadership Studies Programs: A System-level Method and Analysis of Leadership Programming in the State of Kansas. Manuscript submitted for publication.

National Clearinghouse for Leadership Programs. (2016). Curricular programs. Retrieved from https://nclp.umd.edu/resources/CurricularPrograms.aspx

Nabatchi, T. (2012). An introduction to deliberative civic engagement. In T. Nabatchi, J. Gastil, G. M. Weiksner, and M. Leighninger (Eds.), Democracy in motion: Evaluating the practice and impact of deliberative civic engagement (pp. 3-18). New York: Oxford University Press.

O’Malley E. \& Cebula, A. (2015). Your leadership edge: Lead anytime, anywhere. Wichita, KS: Kansas Leadership Center Press.

Ospina, S., \& Foldy, E. G. (2016). Collective Dimensions of Leadership. In A. Farazmand (Ed.), Global Encyclopedia of Public Administration, Public Policy and Governance. Springer. https://doi.org/10.1007/978-3-319-31816-5_2202-1

Ospina, S., \& Schall, E. (2001). Leadership (Re)Constructed: How lens matters. Paper presented at the APPAM Research Conference, Washington, DC. Retrieved from:

http://wagner.nyu.edu/community/faculty/sonia-m-ospina\#showMore--773

Ospina, S. M., Foldy, E. G., El Hadidy, W., Dode, J. Hoffman-Panila, A., \& Su, C. (2012). Social change leadership as relational leadership. In M. Uhl-Bien and S. M. Ospina (Eds.), Advancing relational leadership research: A dialogue among perspectives (pp. 255-302). Charlotte, NC: Information Age Publishing.

Owen, J. E. (2012). Findings from the multi-institutional study of leadership institutional survey: A national report. College Park, MD: National Clearinghouse for Leadership Programs

Priest, K. L. and Kliewer, B. W. (2017), Introduction: Advancing leadership studies through community-engaged Scholarship. Journal of Leadership Studies, 11(1), 36-39. doi: $10.1002 / \mathrm{jls} .21510$

Seemiller, C. \& Priest, K. L. (2015). The hidden "who" in leadership education: conceptualizing leader educator professional identity development. Journal of Leadership Education, 14(3), 132-151. doi: 1012806/V14/I3/T2 
Seemiller, C. \& Priest, K. L. (2017). Leadership educator journeys: Expanding a model of leadership educator professional identity development. Journal of Leadership Education, 16(2), 1-22. doi: 1012806/V16/I2/R1

Tillapaugh, D., \& Haber-Curran, P. (Eds.). (2017). New Directions for Student Leadership: No. 154. Critical perspectives on gender and student leadership. San Francisco, CA: JosseyBass.

Wenger, E. (1998). Communities of practice: Learning, meaning, and identity. New York: Cambridge University Press.

Zimmerman-Oster, K., \& Burkhardt, J. C. (2000). Leadership in the making: Impact and insights from leadership development programs in U.S. colleges and universities. Battle Creek, MI: W. K. Kellogg Foundation.

\section{Author Biographies}

Kerry L. Priest, Ph.D. is an Assistant Professor in the Mary Lynn and Warren Staley School of Leadership Studies at Kansas State University. Her undergraduate and graduate courses focus on civic leadership development, socially responsible leadership, community engagement and organizing. Kerry's research agenda explores the intersections of leadership development and engaged teaching and learning in higher education, with an emphasis on questions that emerge from interpretative, collaborative frameworks of social change. Her scholarship also addresses questions related to student leader identity and leadership educator identity. Kerry earned her Ph.D. from Virginia Tech and Master's degree from the University of Georgia. kerryp@ksu.edu.

Brandon W. Kliewer, Ph.D. is an assistant professor of civic leadership in the Mary Lynn and Warren Staley School of Leadership Studies at Kansas State University. Brandon specializes in deliberative civic engagement, democratic theory, and approaches to community-engaged scholarship that focus on collaboration and partnership. He is currently working on a series of manuscripts that report the results of civic leadership development programs, deliberative civic engagement forums, and community engagement theories and practices. His scholarship often involves undergraduate \& graduate students, community members, and working professionals in ways that create the conditions to mobilize new knowledge in order to make progress on tough challenges. Brandon holds a Ph.D. from The University of Georgia in political science and a Master's degree in political science from Virginia Polytechnic Institute and State University. bliewer@ksu.edu.

Clinton M. Stephens, Ph.D. is Director of the Leadership Studies and assistant professor at Emporia State University. Stephens coordinates the Minor in Leadership and teaches courses in leadership studies. Stephens continues his research that focuses on assessing the effectiveness of courses and workshops to develop participants' leadership capacity. Stephens completed a B.S. in Business Administration at Kansas State University in 2002, a M.S. at Oklahoma State University in 2005 and a Ph.D. in 2012 at Iowa State University. cmsteph@emporia.edu. 